\title{
Kadish Stage A Olfactory Neuroblastoma
}

National Cancer Institute

\section{Source}

National Cancer Institute. Kadish Stage A Olfactory Neuroblastoma. NCI Thesaurus.

Code C6853.

An olfactory neuroblastoma that is confined to the nasal cavity 